\title{
Functional and occupational characteristics predictive of a return to work within 18 months after stroke in Japan: implications for rehabilitation
}

\author{
Hirotaka Tanaka • Toshihiro Toyonaga • \\ Hideki Hashimoto
}

Received: 24 October 2012/ Accepted: 3 May 2013/Published online: 16 May 2013

(C) The Author(s) 2013. This article is published with open access at Springerlink.com

\begin{abstract}
Objective This study examined clinical, functional, and occupational factors associated with return to work within 18 months after stroke, specifically focusing on the impact of higher cortical dysfunction on return to work in the chronic phase.

Methods This prospective cohort study in 21 hospitals specializing in clinical and occupational health recruited consecutive working-age inpatients receiving acute care for their first stroke $(n=351)$. A unified database was used to extract patient information from hospital records at the time of admission, discharge, and follow-up at 18 months post-stroke. Cox proportional hazard regression analysis was conducted to determine clinical, functional, and occupational factors influencing return to work within 18 months.
\end{abstract}

H. Tanaka $(\bowtie)$

Department of Rehabilitation, Chubu Rosai Hospital, Japan Occupational Health and Welfare Organization,

1-10-6 Komei, Minato-ku, Nagoya 455-8530, Japan

e-mail: tanakahirochubu@yahoo.co.jp

H. Tanaka

Clinical Research Center for Worker's Rehabilitation, Japan Occupational Health and Welfare Organization, Kitakyushu, Japan

T. Toyonaga

Kyushu Rosai Hospital Center for Preventive Medicine, Japan Occupational Health and Welfare Organization,

Kitakyushu, Japan

H. Hashimoto

Department of Health Economics and Epidemiology Research,

The University of Tokyo School of Public Health, Tokyo, Japan
Results Of 351 registered stroke patients (280 males, 71 females, mean age $\pm \mathrm{SD}, 55.3 \pm 7.2$ years) who met inclusion criteria, 250 responded to the follow-up survey and 101 were lost to follow-up. Half (51\%) succeeded in returning to work during the 18-month follow-up after stroke onset. After adjusting for age, gender, and Barthel index at initial rehabilitation, the following factors were identified as significant predictors of a return to work: white-collar versus blue-collar occupation (hazard ratio (HR) $1.5 ; 95 \%$ confidence interval (CI) 1.1-2.2), no aphasia (HR 3.0; $95 \%$ CI 1.5-5.9), no attention dysfunction (HR 2.0; $95 \%$ CI 1.0-4.0), and walking ability (HR 3.1; $95 \%$ CI 1.3-7.1).

Conclusions This study indicated the importance of tailored rehabilitation to alleviate the impact of higher cortical dysfunction and to support return to work by stroke survivors.

Keywords Stroke - Employment - Occupational factors · Rehabilitation $\cdot$ Speech disorders

\section{Introduction}

A return to work plays an important role in the occupational health and rehabilitation of working-age post-stroke patients. Previous studies, including our own, identified determinants of early return to work in terms of functional and socioeconomic conditions of the patients (Saeki and Toyonaga 2010; Tanaka et al. 2011). These previous studies focused on the patient's condition in the pre-stroke, hospitalized, and at-discharge periods, since these will predict the functional recovery which is expected within 3-6 months after onset (Bonita and Beaglehole 1988). However, the impact of higher cortical dysfunction has 
been poorly studied apart from a study by Tanaka et al. (2011) in which the authors identified that higher cortical dysfunction significantly reduced the chance of very early return to work within 1 month after discharge in those with mild physical impairment. Since the recovery in higher cortical function is likely to be observed several months after a stroke and into the chronic period after 6 months (Ferro and Crespo 1988), the influence of higher cortical dysfunction on return to work in the chronic phase could be more important than in the earlier phase. Furthermore, the earlier study did not specify what type of higher cortical function is related to return to work among those with different levels of physical impairment. In this study, we specifically focused on the impact of higher cortical dysfunction on return to work in the chronic phase, in addition to the functional and social factors discussed in previous studies. Since the rehabilitation of higher cortical dysfunction often requires a distinct set of resources compared with that required for physical dysfunction, we believe that the results of this study will provide information on the need for cognitive rehabilitation in the chronic stage of stroke recovery to enable return to work.

\section{Methods}

\section{Participants}

The study was performed on the same prospective cohort as in Tanaka et al. (2011). We included consecutive stroke patients aged between 15 and 64 years admitted to 21 hospitals between February 1, 2005 and July 31, 2006 for acute care of a first stroke event and who were in work at the time of the onset of stroke $(n=351)$. We excluded patients who were classified as a housewife or student. The hospitals belong to a nonprofit organization that provides special attention for occupation-related conditions and were founded by the Ministry of Health, Labour and Welfare of Japan. Stroke was diagnosed using the international classification of diseases, 10th revision (ICD-10) codes for cerebral hemorrhage, cerebral infarction, or subarachnoid hemorrhage.

\section{Outcome measure}

The outcome was return to work after stroke, which was defined as active employment in formal paid work on a full-time or part-time basis which was identified at followup 18 months after the onset of stroke. The information was reported directly by patients, by physiatrists at the outpatient clinic interviewing patients, or by trained clerical staff interviewing patients by telephone at 18 months after onset.

\section{Procedures}

A unified electronic data format was used to extract patient information from hospital records at the time of admission, discharge, and follow-up 18 months post-stroke. Data were collected on history and lifestyle factors, demographic factors, diagnostic factors, functional factors, and occupational factors. Physiatrists interviewed patients to obtain information regarding history and lifestyle factors at initial rehabilitation and collected clinical and diagnostic factors at discharge from medical records. Higher cortical dysfunction (brain impairment related to behavior, cognition, and language that cannot be explained by motor paralysis or sensory or perception disorders) was diagnosed by neurologists using the neurological examination based on higher cortical dysfunction diagnosis guidelines (Japanese Ministry of Health, Labour and Welfare 2007), the Standard Language Test of Aphasia (Japan Society for Higher Brain Dysfunction 2003), the Mini-Mental State Examination (Folstein et al. 1975), the line bisection test, and the Kohs block test. Radiologists independently and in a blinded manner made diagnoses regarding etiology, anatomical location, and size of stroke by neuroradiological imaging.

Occupational therapists evaluated functional factors with the modified Rankin scale (mRS) (van Swieten et al. 1988) and the Barthel index (BI) (Malloney and Barthel 1965). The $\mathrm{BI}$ is a measure of functional ability in personal care including self-care, bowel and bladder sphincter control, and mobility. Job type was classified according to the Japanese standard classification of occupations (Japanese Ministry of Health, Labour and Welfare 1997). We classified the following jobs as white collar: clerks, technicians, highly skilled professionals, directors, and managers. Unskilled workers, production-line/machine workers, drivers, skilled manual workers, farm/horticulture workers, and service workers were classified as blue collar.

Potential predictors of return to work within the 18-month follow-up after onset were selected according to the literature (Tanaka et al. 2011; Treger et al. 2007; Wozniak and Kittner 2002) and included age, gender, education, dysphagia, spasticity, visuospatial neglect (failing to report, respond, or orient to visual stimuli presented at the side opposite a brain lesion), aphasia (an acquired disorder of all language modalities, including verbal expression, auditory comprehension, written expression, and reading comprehension), attention dysfunction, memory dysfunction, intelligence dysfunction, etiological diagnosis, side of hemiplegia, BI at first rehabilitation, upper extremity function, walking ability, job type, work position, and mental stress at work.

This study was approved by the ethics committees of the Japan Occupational Health and Welfare Organization and 
the internal review board of each participating hospital. Written informed consent was obtained from each patient.

\section{Statistical analyses}

Cox proportional hazard regression analysis was conducted with adjustment for three strong predictors of return to work, namely age, gender, and BI at initial rehabilitation, in order to select candidate variables from clinical, functional, and occupational factors for multivariable analysis. In a previous study, we used mRS at discharge because of a ceiling effect of BI in patients with relatively mild disability. In this study, we used BI at initial rehabilitation as an adjusting factor because it should more sensitively reflect the initial condition before rehabilitation. At this stage, $p<0.10$ was used as the inclusion criterion. The Kaplan-Meier method was used to confirm the proportional hazard assumption of each variable. The selected candidate variables were further tested using forward stepwise regression analysis to obtain a final model to predict the likelihood of return to work within 18-month follow-up after stroke. In this final model, $p<0.05$ was conventionally chosen as the level of statistical significance. Hazards ratios (HRs) were computed based on the estimated coefficients in Cox proportional hazard regression analysis. Since our previous study suggested that the impact of higher cortical dysfunction might depend on other conditions of the patient, we additionally tested whether the impact of higher cortical dysfunction was observed across job types, age strata, and initial severity of physical dysfunction. All statistical analyses were conducted using SPSS for Windows, version 19 (SPSS Inc., Chicago, IL, USA).

\section{Results}

Of 351 registered stroke patients (280 males, 71 females, mean age \pm standard deviation (SD), $55.3 \pm 7.2$ years, age range 21-64 years), met the inclusion criteria. As for etiology, $36 \%$ were diagnosed with cerebral hemorrhage, $54 \%$ with cerebral infarction, and $10 \%$ with subarachnoid hemorrhage. At the 18-month follow-up, 250 responded to the survey (Table 1), while 101 were lost to follow-up. These two groups of responders and non-responders were not significantly different in terms of age (mean age \pm SD: $55.4 \pm 7.0$ and $54.8 \pm 7.6$ years, respectively $(p=0.481))$, BI at onset (mean score \pm SD: $38.6 \pm 37.6$ and $42.8 \pm 40.0$, respectively $(p=0.382)$ ), BI at initial rehabilitation (mean score $\pm \mathrm{SD}: \quad 55.3 \pm 36.7$ and $54.2 \pm 39.0$, respectively $(p=0.813)$ ), and BI at discharge (mean score \pm SD: $89.4 \pm 21.7$ and $90.1 \pm 20.1$, respectively $(p=0.774)$ ). Among those who were followed-up, 128 patients (51\%:
$51.5 \%$ of men, $50 \%$ of women) reported a successful return to work within 574 days after stroke onset (Fig. 1).

After adjustment for age, gender, and BI at initial rehabilitation, the following variables showed significant associations with the return to work at 18-month follow-up: job type, work position, etiological diagnosis, upper extremity function, walking ability, spasticity, visuospatial neglect, aphasia, attention dysfunction, memory dysfunction, and intelligence dysfunction. Since etiological diagnosis and work position violated proportional hazard assumption in visual diagnosis with Kaplan-Meier curves, we excluded these variables in further analysis, leaving nine variables for further multivariable analysis (Table 2).

In stepwise Cox proportional hazard regression analysis, with adjustment for age, gender, and BI at initial rehabilitation, significant predictors of return to work at 18-month follow-up after stroke were job type, aphasia, attention dysfunction, and walking ability (Table 3 ). Specifically, those who had independent walking ability, were engaged in white-collar jobs, and were without aphasia and attention dysfunction were significantly more likely to return to work. Age (HR 0.96; $95 \%$ confidence interval (CI) 0.94-0.98) and BI at initial rehabilitation (HR 1.01; $95 \%$ CI 1.00-1.01) remained significant predictors after adjustment for walking ability, white-collar job, aphasia, and attention dysfunction.

Since job type, age, and BI at initial rehabilitation were significant influential factors, we further tested whether the impact of aphasia and attention dysfunction differed according to the levels of these properties. Stratified analysis by job type found that age, BI at initial rehabilitation, and no aphasia were significant predictors of return to work in white-collar workers, while age, BI at initial rehabilitation, walking capability, and no aphasia were significant among blue-collar workers. Lack of aphasia showed a HR for return to work of 4.0 (95\% CI 1.6-10.1) among whitecollar workers and 2.8 (95\% CI 1.1-7.2) among blue-collar workers. The HR of no attention dysfunction did not differ by job type and was similar for white-collar and blue-collar workers. Stratification by age revealed that those aged 56 and younger had no aphasia, no attention dysfunction, and walking ability as significant predictors of return to work, while those aged 57 and over had age and BI at initial rehabilitation as significant predictors. The estimated HRs for return to work among younger age patients were 3.2 (95\% CI 1.5-6.7) for no aphasia and 2.8 (95\% CI 1.1-7.3) for no attention dysfunction. Finally, the stratification by BI scores at initial rehabilitation showed that age, no attention dysfunction, and walking ability were significant predictors among those with initial BI score less than 60, and age, gender, and no aphasia were significant predictors among those with initial BI score of 60 and greater. The HR of no aphasia was 3.2 (95 \% CI 1.3-8.0) among those with milder 
Table 1 Basic characteristics of subjects studied $(n=250)$

\begin{tabular}{|c|c|c|c|}
\hline Variables & Number of patients & Returned to work $(\%)$ & $p$ \\
\hline \multicolumn{4}{|l|}{ Demographic factors } \\
\hline Gender & & & 0.874 \\
\hline Male & 202 & 51.5 & \\
\hline Female & 48 & 50 & \\
\hline Education & & & 0.03 \\
\hline College & 44 & 70.5 & \\
\hline Junior college & 18 & 55.6 & \\
\hline High school & 123 & 49.6 & \\
\hline Less than high school & 34 & 38.2 & \\
\hline \multicolumn{4}{|l|}{ Diagnostic factors } \\
\hline Diagnosis & & & 0.017 \\
\hline Cerebral hemorrhage & 90 & 38.9 & \\
\hline Cerebral Infarction & 133 & 57.1 & \\
\hline Subarachnoid hemorrhage & 23 & 60.9 & \\
\hline Side of hemiplegia & & & 0.007 \\
\hline Right & 124 & 42.7 & \\
\hline Left & 85 & 56.5 & \\
\hline Bilateral & 7 & 28.6 & \\
\hline None & 28 & 75 & \\
\hline Weakness in hemiplegic upper extremity & & & $<0.001$ \\
\hline Normal or mild & 162 & 60.5 & \\
\hline Moderate & 45 & 40 & \\
\hline Severe & 39 & 23.1 & \\
\hline Weakness in hemiplegic lower extremity & & & $<0.001$ \\
\hline Normal or mild & 188 & 60.1 & \\
\hline Moderate & 45 & 26.7 & \\
\hline Severe & 12 & 0 & \\
\hline Dysphasia & & & $<0.001$ \\
\hline No & 227 & 54.6 & \\
\hline Yes & 18 & 11.1 & \\
\hline Dysarthria & & & 0.035 \\
\hline No & 189 & 55 & \\
\hline Yes & 57 & 38.6 & \\
\hline Aphasia & & & $<0.001$ \\
\hline No & 201 & 57.7 & \\
\hline Yes & 44 & 22.7 & \\
\hline Visuospatial neglect & & & $<0.001$ \\
\hline No & 216 & 56 & \\
\hline Yes & 29 & 13.8 & \\
\hline Apraxia & & & $<0.001$ \\
\hline No & 228 & 54.4 & \\
\hline Yes & 17 & 5.9 & \\
\hline Shoulder-hand syndrome & & & $<0.001$ \\
\hline No & 229 & 54.6 & \\
\hline Yes & 17 & 5.9 & \\
\hline Shoulder subluxation & & & $<0.001$ \\
\hline No & 218 & 56.4 & \\
\hline Yes & 28 & 10.7 & \\
\hline
\end{tabular}


Table 1 continued

\begin{tabular}{|c|c|c|c|}
\hline Variables & Number of patients & Returned to work (\%) & $p$ \\
\hline Spasticity & & & 0.003 \\
\hline No & 217 & 54.8 & \\
\hline Yes & 29 & 24.1 & \\
\hline Depression & & & 0.808 \\
\hline No & 228 & 50.9 & \\
\hline Yes & 18 & 55.6 & \\
\hline Attention dysfunction & & & $<0.001$ \\
\hline No & 197 & 58.4 & \\
\hline Yes & 48 & 22.9 & \\
\hline Memory dysfunction & & & $<0.001$ \\
\hline No & 201 & 57.7 & \\
\hline Yes & 43 & 20.9 & \\
\hline Intelligence dysfunction & & & 0.001 \\
\hline No & 209 & 56 & \\
\hline Yes & 35 & 25.7 & \\
\hline Fatigability & & & 0.002 \\
\hline No & 182 & 57.1 & \\
\hline Yes & 63 & 34.9 & \\
\hline \multicolumn{4}{|l|}{ Functional factors } \\
\hline $\mathrm{mRS}^{*}$ at initial rehabilitation & & & $<0.001$ \\
\hline 0 & 3 & 33.3 & \\
\hline 1 & 26 & 69.2 & \\
\hline 2 & 42 & 71.4 & \\
\hline 3 & 36 & 58.3 & \\
\hline 4 & 71 & 49.3 & \\
\hline 5 & 68 & 29.4 & \\
\hline $\mathrm{mRS}^{*}$ at discharge & & & $<0.001$ \\
\hline 0 & 24 & 62.5 & \\
\hline 1 & 99 & 71.7 & \\
\hline 2 & 63 & 49.2 & \\
\hline 3 & 32 & 18.8 & \\
\hline 4 & 22 & 13.6 & \\
\hline 5 & 5 & 0 & \\
\hline Walking ability & & & $<0.001$ \\
\hline Independent & 190 & 61.6 & \\
\hline Assisted & 55 & 14.5 & \\
\hline \multicolumn{4}{|l|}{ Treatment factor } \\
\hline Surgical operation & & & 0.331 \\
\hline Yes & 47 & 44.7 & \\
\hline No & 195 & 53.3 & \\
\hline \multicolumn{4}{|l|}{ Occupational factors } \\
\hline Job type & & & 0.013 \\
\hline Blue collar & 156 & 44.9 & \\
\hline White collar & 94 & 67.1 & \\
\hline Work position & & & 0.001 \\
\hline Manager & 36 & 47.2 & \\
\hline Head of department & 44 & 72.7 & \\
\hline Regular employee & 115 & 52.2 & \\
\hline Other & 41 & 29.3 & \\
\hline
\end{tabular}


Table 1 continued

\begin{tabular}{|c|c|c|c|}
\hline Variables & Number of patients & Returned to work $(\%)$ & $p$ \\
\hline Full time or part time & & & 0.127 \\
\hline Full time & 198 & 55.1 & \\
\hline Part time & 35 & 37.1 & \\
\hline Mental stress at work & & & 0.011 \\
\hline No & 167 & 45.5 & \\
\hline Yes & 83 & 62.7 & \\
\hline Approach from physician to patient and family & & & 0.019 \\
\hline Yes & 106 & 60.4 & \\
\hline No & 130 & 44.6 & \\
\hline Approach from physician to rehabilitation stuff & & & 0.001 \\
\hline Yes & 105 & 63.8 & \\
\hline No & 132 & 43.2 & \\
\hline Employment status at discharge & & & $<0.001$ \\
\hline Employed & 185 & 60 & \\
\hline Unemployed & 41 & 12.2 & \\
\hline Patient wish for return to work & & & $<0.001$ \\
\hline Want & 170 & 61.2 & \\
\hline Do not want & 35 & 22.9 & \\
\hline Family wish for patient return to work & & & 0.199 \\
\hline Want & 131 & 58.8 & \\
\hline Do not want & 17 & 41.2 & \\
\hline Satisfaction with social participation & & & $<0.001$ \\
\hline Yes & 82 & 59.9 & \\
\hline No & 55 & 55 & \\
\hline Collaboration with industrial physicians & & & 0.062 \\
\hline Yes & 23 & 78.3 & \\
\hline No & 108 & 56.5 & \\
\hline Cooperation of workplace supervisors & & & 0.016 \\
\hline Yes & 50 & 78 & \\
\hline No & 61 & 55.7 & \\
\hline Coordination of the work environment & & & 1 \\
\hline Yes & 10 & 70 & \\
\hline No & 94 & 71.3 & \\
\hline Cooperation with vocational rehabilitation & & & 0.41 \\
\hline Yes & 17 & 76.5 & \\
\hline No & 97 & 62.9 & \\
\hline Support of medical institutions on return to work & & & 0.001 \\
\hline Yes & 43 & 74.4 & \\
\hline No & 131 & 45.8 & \\
\hline
\end{tabular}

Total number of patients does not always equal 250 because of missing data

Score 0 no symptoms, Score 1 no significant disability despite symptoms, Score 2 slight disability, Score 3 moderate disability, Score 4 moderately severe disability, and Score 5 severe disability

* mRS-Rankin scale impact on very early return to work among those with only very mild physical impairment (Tanaka et al. 2011). In the current study, we additionally revealed that aphasia and attention dysfunction also had a significant impact on return to work within 18 months after stroke onset.

Previous studies indicated that neuropsychological impairments impact on vocational prognosis in the chronic stage of stroke. Kotila et al. (1984) showed that impairments in intelligence and memory had a major negative 


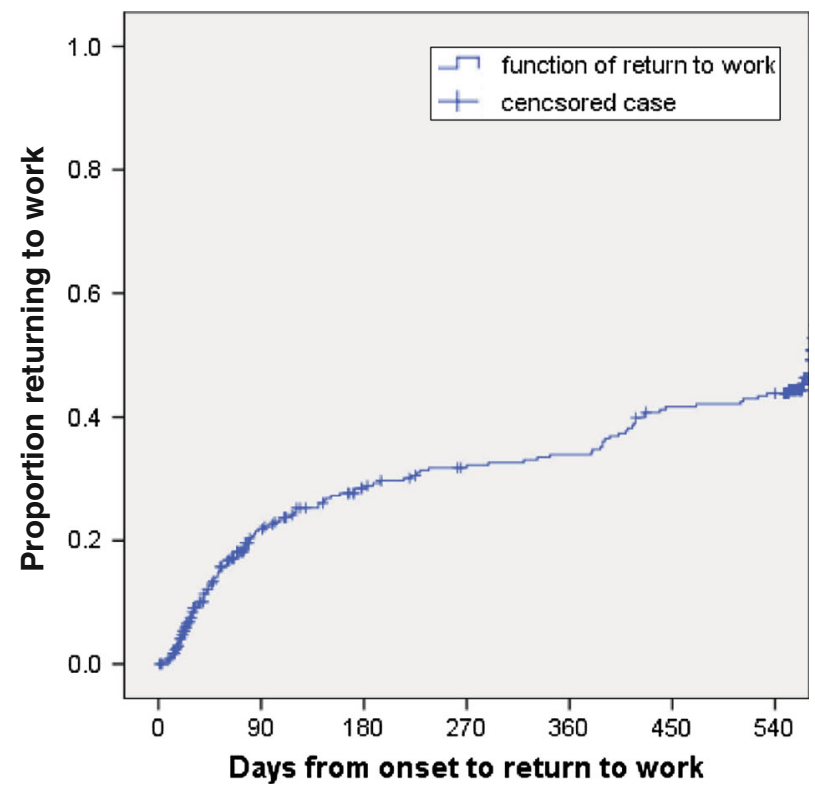

Cumulative no. at risk

$\begin{array}{lcccccc}\text { Return to work } & 68 & 85 & 93 & 98 & 116 & 128 \\ \text { Censored } & 75 & 92 & 99 & 99 & 101 & 202 \\ \text { Remaining cases } & 208 & 174 & 159 & 154 & 134 & 21\end{array}$

Fig. 1 Proportion of patients returning to work during the 18 months after stroke onset

influence on return to work in the 12 months from stroke onset. Although there is little research on the relationship between attention dysfunction and return to work in stroke patients, some studies in traumatic brain injury cases reported that recovery of attention significantly improved return to work (Dawson et al. 2004; Mateer and Sira 2006). Vilkki et al. (2004) examined patients who had secondary cerebral infarction after aneurysmal subarachnoid hemorrhage and found that left-hemisphere infarctions causing deficits in verbal memory were likely to result in a failure to return to work within 1 year of the accident. Doucet et al. (2012) also reported that negative prognostic factors for a return to work after 3-year follow-up were language disorders (aphasia and dysarthria). The results of our study clearly indicated that patients without these factors had a significantly better chance of a return to work in the chronic phase.

The current study also suggested that the effect of aphasia and attention dysfunction varied according to concurrent conditions of stroke patients. Patients without aphasia showed a significantly higher chance of returning to work regardless of job types, suggesting that verbal communication with worksite colleagues could influence vocational prognosis in general (Black-Schaffer and Osberg 1990). In contrast, lack of attention dysfunction and aphasia was a significant factor among younger workers, but not among older workers. This difference according to age may indicate that differences in the levels of job complexity and demand may affect the chance of returning to work, especially among younger stroke survivors. It was also noteworthy that the role of attention dysfunction was
Table 2 Selected candidate variables associated with return to work within 18 months of onset after adjusting for age, gender, and Barthel index at initial rehabilitation

\begin{tabular}{llll}
\hline Variables & Reference & Hazard ratio & $\begin{array}{l}\text { 95 \% confidence } \\
\text { interval }\end{array}$ \\
\hline Job type & White collar versus blue collar & 1.6 & $1.1-2.2$ \\
Upper extremity function & Normal or mild versus severe & 3.6 & $1.8-7.4$ \\
& Moderate versus severe & 2.5 & $1.1-5.6$ \\
Walking ability & Independent versus dependent & 4.8 & $2.2-10.6$ \\
Spasticity & No versus yes & 2.9 & $1.3-6.3$ \\
Visuospatial neglect & No versus yes & 4.7 & $1.7-12.9$ \\
Aphasia & No versus yes & 3.3 & $1.7-6.3$ \\
Attention dysfunction & No versus yes & 3.1 & $1.6-6.0$ \\
Memory dysfunction & No versus yes & 2.8 & $1.4-5.6$ \\
Intelligence dysfunction & No versus yes & 2.2 & $1.1-4.4$ \\
\hline
\end{tabular}

Table 3 Multivariable model to predict return to work within 18 months after onset, analyzed by stepwise Cox proportional hazard analysis

\begin{tabular}{llll}
\hline Variables & Reference & Hazard ratio & $95 \%$ confidence interval \\
\hline Job type & White collar versus blue collar & 1.5 & $1.1-2.2$ \\
Aphasia & No versus yes & 3.0 & $1.5-5.9$ \\
Attention dysfunction & No versus yes & 2.0 & $1.0-4.0$ \\
Walking ability & Independent versus dependent & 3.1 & $1.4-7.1$
\end{tabular}

Adjusted for age, gender, and Barthel index at initial rehabilitation

In total, 311 cases were used in the analysis because of missing observations 
significant among those with moderate to severe disability, while the role of aphasia was significant among the mildly disabled. Again, this may be explained by different job demands for patients with mild disability and for those with more severe disabilities. Demanding jobs with more complex communication requirements may be more likely to be assigned to patients with mild disability, while severely disabled patients may be assigned less demanding jobs that may not require so much communication and attention capabilities. Although the explanation above is only speculative because we did not have detailed information on the nature of the patients' jobs, our findings may indicate the need of tailored job reallocation and rehabilitation programs according to patient's age, former job, and remaining functions after stroke.

Persons with more skilled forms of employment may have a greater chance of returning to work because such forms of employment may allow an appropriate redesign of working conditions even for patients in the chronic stage of stroke recovery. The identified impact of aphasia and attention dysfunction may be alleviated through intensive rehabilitation treatment of higher functions. Hinckley (2002) noted that $62 \%$ of chronic aphasia patients from an intensive treatment program were in employment 2 years after discharge. Aphasia rehabilitation may also promote community reintegration, workplace flexibility, and enhancement of social support to the patients that further enables the person with aphasia to return to a former job.

The current study confirmed that job type remained significantly related to the chance of employment after 18 months from onset as well as to very early return to work, which was consistent with findings in previous studies in Japan and in other countries (Saeki et al. 1993; Howard et al. 1985; Hannerz et al. 2011; Vestling et al. 2003). Some studies reported that age was not related to very early return to work, but our study found that younger age was significantly associated with a return to employment within 18 months. Previous rehabilitation studies suggested that there were no differences in the chance of recovery from walking disability, attention dysfunction, and aphasia according to age, and they recommended intensive rehabilitation regardless of patient age (Pickersgill and Lincoln 1983; Luk et al. 2006; Denti et al. 2008). However, several studies, including this study, revealed that older age was related to a lower probability of returning to work in the chronic stage (Howard et al. 1985; Hannerz et al. 2011; Saeki 2000, Busch et al. 2009; Wozniak et al. 1999). We speculate that social as well as physiological conditions may play a role in employment rehabilitation of older patients who face restrictive social conditions for labor participation. Investigation of social aspects of rehabilitation into the working environment is warranted to further facilitate return to work of stroke patients irrespective of age.
In our analysis, the BI and walking ability in the early phase were related to return to work within 18 months. In our previous study on early return to work (Tanaka et al. 2011), we used the mRS at discharge as a predictor of return to work. Since walking and functional abilities reflected in BI are influential factors determining the level of the mRS, the results confirmed that functional and walking disability similarly affected the chance of return to work in very early as well as in the chronic phase.

We could not use the factors of family wish for patient return to work, collaboration with industrial physicians, cooperation of workplace supervisors, coordination of the work environment, provision of vocational rehabilitation, and support of medical institutions on return to work as independent variables in the multivariate analysis because of the large number of missing observation. The impact of support from patient's family and former work place on return to work deserves further investigation in future research.

This study had several limitations. First, at the 18-month follow-up, 250 responded to the survey, while 101 were lost to follow-up. Of the 101 patients, four had died and 21 survived, but did not respond, while the other 76 patients had lost contact. There was no significant difference between responders and lost patients in terms of age, $\mathrm{BI}$ at onset, $\mathrm{BI}$ at initial rehabilitation, and BI at discharge. However, the high attrition rate could lead to bias in our analysis.

Second, there was a considerable amount of missing information on non-medical factors that may affect the likelihood of return to work, such as family wish for patient return to work and collaboration with industrial physicians. Inclusion of non-medical support from family and workplace might have modified the final model in predicting success in return to work 18 months after stroke.

Third, although our results indicate rehabilitation program for higher cortical dysfunction may be effective to enhance the chance of return to work among young patients with mild physical disability, we could not directly show cost-effectiveness of such program due to our data limitation, which remains to be articulated in future research.

In conclusion, specific types of higher cortical dysfunction such as aphasia and attention dysfunction as well as walking ability and job type had a significant impact on return to work among stroke survivors within 18 months of onset, after adjustment for age, gender, and physical dysfunction at initial rehabilitation. The impact of higher cortical dysfunction was more likely to be observed among young and mildly disabled patients, suggesting the need for a tailored rehabilitation program and job redesign for patients with higher cortical dysfunction after stroke. This study indicated the importance of cognitive rehabilitation to alleviate the impact of higher cortical dysfunction and to support return to work by stroke survivors. 
Acknowledgments The authors are grateful to Mikio Sumida, MD, Akihiro Tokuhiro, MD, Akihiro Toyota, MD, Satoru Saeki, MD, Toshikatu Tominaga, MD, and the staff of 21 Rosai hospitals that participated in this study. This research is a part of the research and development and dissemination projects related to the 13 fields of occupational injuries and illnesses of the Japan Occupational Health and Welfare Organization (Primary Investigator: Toshihiro Toyonaga).

Conflict of interest The authors declare that they have no conflict of interest.

Open Access This article is distributed under the terms of the Creative Commons Attribution License which permits any use, distribution, and reproduction in any medium, provided the original author(s) and the source are credited.

\section{References}

Black-Schaffer RM, Osberg JS (1990) Return to work after stroke: development of a predictive model. Arch Phys Med Rehabil 71:285-290

Bonita R, Beaglehole R (1988) Recovery of motor function after stroke. Stroke 19:1497-1500

Busch MA, Coshall C, Heuschmann PU, McKevitt C, Wolfe CD (2009) Sociodemographic differences in return to work after stroke: the South London Stroke Register (SLSR). J Neurol Neurosurg Psychiatry 80:888-893

Dawson DR, Levine B, Schwartz ML, Stuss DT (2004) Acute predictors of real-world outcomes following traumatic brain injury: a prospective study. Brain Inj 18:221-238

Denti L, Agosti M, Franceschini M (2008) Outcome predictors of rehabilitation for first stroke in the elderly. Eur J Phys Rehabil Med 44:3-11

Doucet T, Muller F, Verdun-Esquer C, Debelleix X, Brochard P (2012) Returning to work after a stroke: a retrospective study at the Physical and Rehabilitation Medicine Center La Tour de Gassies. Ann Phys Rehabil Med 55:112-127

Ferro JM, Crespo M (1988) Young adult stroke: neuropsychological dysfunction and recovery. Stroke 19:982-986

Folstein MF, Folstein SE, McHugh PR (1975) Mini-mental State. A practical method for grading the cognitive state of patients for the clinician. J Psychiatr Res 12:189-198

Hannerz H, Holbæk Pedersen B, Poulsen OM, Humle F, Andersen LL (2011) A nationwide prospective cohort study on return to gainful occupation after stroke in Denmark 1996-2006. BMJ Open 2:e000180

Hinckley JJ (2002) Vocational and social outcomes of adults with chronic aphasia. J Commun Disord 35:543-560
Howard G, Till JS, Toole JF, Matthews C, Truscott L (1985) Factors influencing return to work following cerebral infarction. JAMA 253:226-232

Japan Society for Higher Brain Dysfunction (2003) Standard language test of aphasia, 2nd ed [in Japanese]

Japanese Ministry of Health, Labour and Welfare (1997) Japanese standard classification of work. [in Japanese]

Japanese Ministry of Health, Labour and Welfare (2007) Higher cortical dysfunction diagnosis guidelines. [in Japanese]

Kotila M, Waltimo O, Niemi ML, Laaksonen R, Lempinen M (1984) The profile of recovery from stroke and factors influencing outcomes. Stroke 15:1039-1044

Luk JKH, Cheung RTF, Ho SL, Li L (2006) Does age predict outcome in stroke rehabilitation? A study of 878 Chinese subjects. Cerebrovasc Dis 21:229-234

Malloney FI, Barthel DW (1965) Functional evaluation: the Barthel index. A simple index of independence useful in scoring improvement in the rehabilitation of the chronically ill. Md State Med J:61-65

Mateer CA, Sira CS (2006) Cognitive and emotional consequences of TBI: intervention strategies for vocational rehabilitation. NeuroRehabilitation 21:315-326

Pickersgill MJ, Lincoln NB (1983) Prognostic indicators and the pattern of recovery of communication in aphasic stroke patients. J Neurol Neurosurg Psychiatry 46:130-139

Saeki S (2000) Disability management after stroke: its medical aspects for workplace accommodation. Disabil Rehabil 22:578-582

Saeki S, Toyonaga T (2010) Determinants of early return to work after first stroke in Japan. J Rehabil Med 42:254-258

Saeki S, Ogata H, Okubo T, Takahashi K, Hoshuyama T (1993) Factors influencing return to work after stroke in Japan. Stroke 24:1182-1185

Tanaka H, Toyonaga T, Hashimoto $H$ (2011) Functional and occupational characteristics associated with very early return to work after stroke in Japan. Arch Phys Med Rehabil 92:743-748

Treger I, Shames J, Giaquinto S, Ring H (2007) Return to work in stroke patients. Disabil Rehabil 42:254-258

van Swieten JC, Koudstaal PJ, Visser MC, Schouten HJA, van Gijn J (1988) Interobserver agreement for the assessment of handicap in stroke patients. Stroke 19:604-607

Vestling M, Tufvesson B, Iwarsson S (2003) Indicators for return to work after stroke and the importance of work for subjective wellbeing and life satisfaction. J Rehabil Med 35:127-131

Vilkki JS, Juvela S, Siironen J, Ilvonen T, Varis J, Porras M (2004) Relationship of local infarctions to cognitive and psychosocial impairments after aneurysmal subarachnoid hemorrhage. Neurosurgery $55: 790-802$

Wozniak MA, Kittner SJ (2002) Return to work after ischemic stroke: a methodological review. Neuroepidemiology 21:159-166

Wozniak MA, Kittner SJ, Price TR, Hebel JR, Sloan MA, Gardner JF (1999) Stroke location is not associated with return to work after first ischemic stroke. Stroke 30:2568-2573 